\title{
Microscopic Findings Severity
}

National Cancer Institute

\section{Source}

National Cancer Institute. Microscopic Findings Severity. NCI Thesaurus. Code C119880.

The degree of something undesirable as determined by microscopic findings. 